\title{
An empirical study of institutional research in a senior high school
}

\author{
Shufang Lin ${ }^{1}$ 'Yih-Jeng Lin ${ }^{2}$, Ching-Ling Wu ${ }^{3}$ \\ ${ }^{1,3}$ Department of Educational Policy and Administration, National Chi Nan University, Nantou, Taiwan \\ ${ }^{2}$ Department of Information Management, Chienkuo Technology University, Changhua, Taiwan
}

\section{Key Words}

Institutional research

Information system

School management

Student recruitment

Received: 30 July 2016

Accepted: 20 September 2016

Published: 19 December 2016

\begin{abstract}
The study investigated a senior high school's Institutional Research (IR) experiment, aiming to provide evidence-based decision-making support to student recruitment policies and practices. Precisely, the study documented and analyzed how IR concepts and techniques could be used to support and benefit school management decision makings. The current IR model is structured with four analysis modules: (1) Enrollment source analysis, (2) School satisfaction questionnaire analysis, (3) Analysis of learning status, and (4) Analysis of teachers' instructional quality. The study contributes to explore the potentials and limitations of IR on guiding school management strategies. Based on this research, new creative concepts and techniques are suggested to be brought into the educational area, and evidence-based decision-making is encouraged. A broader application of Big Data analysis or IR in schools will need more investigations in the future.
\end{abstract}

(C)2016 The Author. Published by TAF Publishing.

\section{INTRODUCTION}

Taiwan's total fertility rate is between the range of $1.065 \%-1.270 \%$ since 2012 to 2014 (Ministry of the Interior, 2016). Furthermore, Taiwan is the least fertility rate country in 2009 worldwide. Low fertility causes many serious problems, especially for school management. Schools around Taiwan currently are challenged by serious student recruitment difficulties resulted from low fertility rate. Administrators of schools need new and effective strategies to improve their school management and attract more students to enroll.

Teachers and administrators actually need to make all kinds of decisions and choices every day to actualize their educational goals. Both creative, effective concepts and information techniques can support and benefit their management decision makings or strategies. As we know, in 1940, Institutional Research (IR) was proposed to effectively deal with America Universities' management issues. Volkwein (2015) thinks that there are three concepts involving IR critical to school management: (1) school affairs reports and strategies analysis; (2) planning, student recruitment, and financial management; (3) quality assurance, learning achievement assessment, program evaluation, efficacy and certificates ( Webber et al. 2015). IR accompanied with Big Data theory and concepts could potentially inspire management strategies including planning, program design and financial decision supporting systems for schools. Meanwhile, according to Big Data theory, if we can collect huge volume, true, valuable and various kinds of data (Jewel, 2015), good quality IR reports will be available to support administrators with evidence-based decision makings. IR is mainly made in both United States of America (USA) and Japan's universities.

\footnotetext{
${ }^{*}$ Corresponding author: Shufang Lin

${ }^{\dagger}$ Email: shoufanglin@yahoo.com.tw
} 
As IR and Big Data's creative concept and information techniques emerging, we are quite curious about its potential and limitation on guiding senior high schools' management. Therefore we are trying to apply a new empirical study of IR in a senior high school not a university. In our IR empirical research, two research questions are hopefully to be well understood. First one is that how to establish a senior high school IR model with Big Data approach. Second one is that how to apply the well-designed IR model to investigate student recruitment policies and practices of a rural senior high school. We design a multiple factored model of Institutional Research in a senior high school and investigate a senior high school's experiment of Institutional Research (IR), aiming to provide evidence-based decision making support to student recruitment policies and practices. Our IR model is structured with four analysis modules: (1) Enrollment Source Analysis; (2) School satisfaction questionnaire analysis; (3) Analysis of Learning Status and (4) Analysis of teachers' instructional quality. Then the above four analysis modules expand into 25 analysis pages. Based on our research, new creative concepts and techniques are suggested to be brought into educational area, and evidence-based decision makings are encouraged. Either broader application of the Big Data analysis or IR in schools will certainly need more investigations in the future.

\section{METHOD AND PROCEDURE}

This study used BI analytic software "Qlikview" to integrate school administration system and designed analysis situations. After literature research (Chiu, 2006; Chien, 2015; Chen, 2014) and reference to researcher's empirical experience, we raised four modules as below--(1) enrollment source analysis; (2) school satisfaction questionnaire analysis; (3) analysis of learning status and (4) analysis of teachers' instructional quality. Four modules develop 25 analysis pages, as table 1 showed. After situations well designed, we try to investigate and form student recruitment policies and practices of a senior high school. With our effort, we hope to assist school administrators to lead and manage their schools creatively and effectively. Figure 1 shows the procedure of enrollment source analysis. Then the structure of school affairs analysis system is as figure 2 shows.

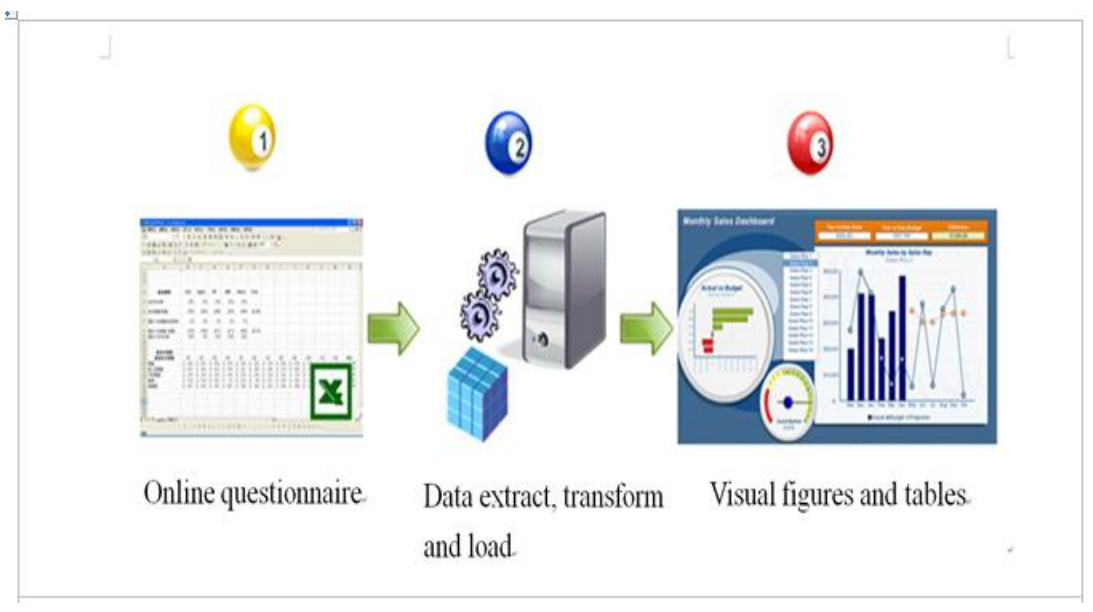

FIGURE 1. The procedure of student source data's analysis 
TABLE 1

Conceptions of mathematics

\begin{tabular}{|c|c|}
\hline Modules & Pages \\
\hline Enrollment Source & 1. The trend analysis of the enrollment from competitor \\
\hline \multirow[t]{3}{*}{ Analysis } & 2. Scores Analysis of Admission placement \\
\hline & 3. Analysis of the sources of students- school sources/ regions \\
\hline & 4. Analysis of the ways of students choose for admission \\
\hline \multirow{7}{*}{$\begin{array}{l}\text { School satisfaction } \\
\text { questionnaire analysis }\end{array}$} & 1. Reputation Impact analysis \\
\hline & 2. Environmental impact analysis \\
\hline & 3. Teacher education and qualifications analysis \\
\hline & 4. Environmental equipment impact analysis \\
\hline & 5. Student Affairs Counseling impact analysis \\
\hline & 6. Course Teaching Effect analysis \\
\hline & 7. Interaction Analysis for social community \\
\hline Analysis of Learning & 1. Diagnosis and analysis of grades \\
\hline \multirow[t]{3}{*}{ Status } & 2. Analysis of individual students' starting aptitude \\
\hline & 3. Academic Performance Analysis \\
\hline & 4. Diagnosis of test questions \\
\hline \multirow{10}{*}{$\begin{array}{l}\text { Analysis of teachers' } \\
\text { instructional quality }\end{array}$} & 1. Teaching assessment analysis -overall analysis \\
\hline & 2. Teaching hours load analysis \\
\hline & 3. Curriculum design index analysis \\
\hline & 4. Index for teaching materials compilation analysis \\
\hline & 5. Multiple perspective index analysis \\
\hline & 6. Adaptive learning index analysis \\
\hline & 7. Effective teaching index analysis \\
\hline & 8. Course improvement Index analysis \\
\hline & 9. Classroom management index analysis \\
\hline & 10. Remedial teaching Index analysis \\
\hline
\end{tabular}

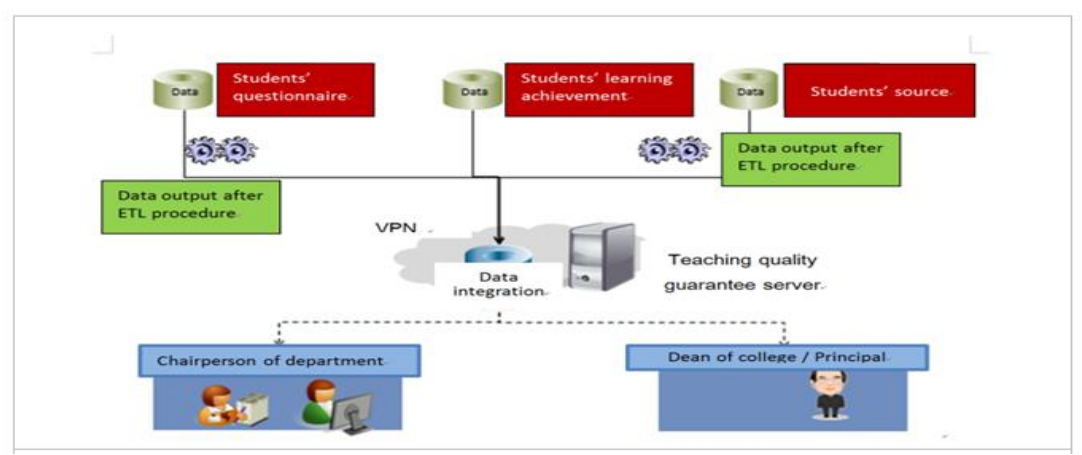

FIGURE 2. The structure of school affairs analysis system

Our research data are collected from school administration system's data base and through questionnaires. After data ETL procedure, well designed modules are used to analyze those data and produce visual figures and tables. Research procedure and structure are as figure 3 shows. 


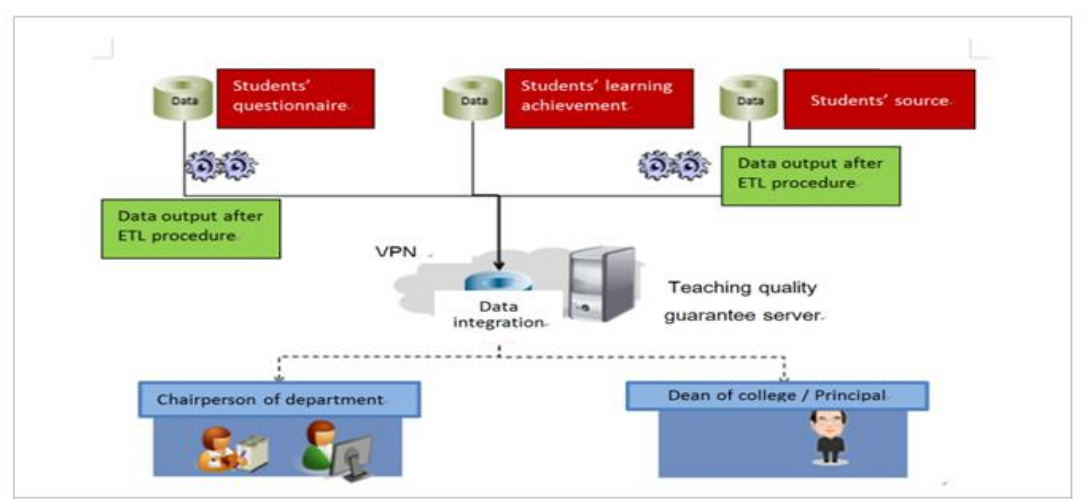

FIGURE 3. Research procedure and structure

\section{RESULTS AND SUGGESTION}

Results

Establish a senior high school IR model with Big Data approach: We raised four modules to construct an IR model--- (1) enrollment source analysis; (2) school satisfaction questionnaire analysis; (3) analysis of learning status and (4) analysis of teachers' instructional quality. Then those four modules develop 25 analysis pages. The effects of this IR model are as follow: (1) improve teachers' instructional quality and students' learning status; (2) reinforce the students' recruitment strategies; (3) provide suggestions for school's informationizing works. 3.1.2 The application of the IR in the senior high school. Figure 4 is the trend analysis of the enrollment from competitors. By this analysis page, we can compare the school's trend of its students' enrollment amount and scores with its competitors. We can get a clear picture of the development of the students' enrollment from this analysis.

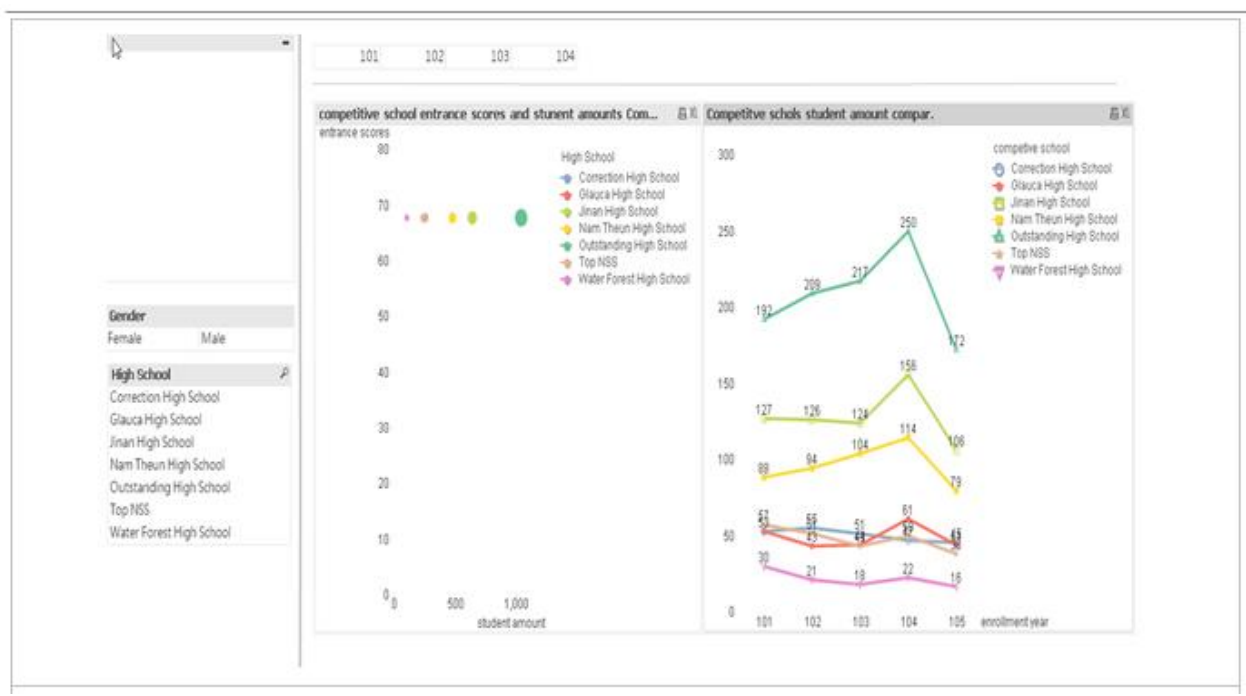

FIGURE 4. The trend analysis of the enrollment from competitors

The scores analysis of admission placement is as figure 5 shows. Through this analysis, we can know the mean scores of admission placement in different academic years or different departments in several academic years. 


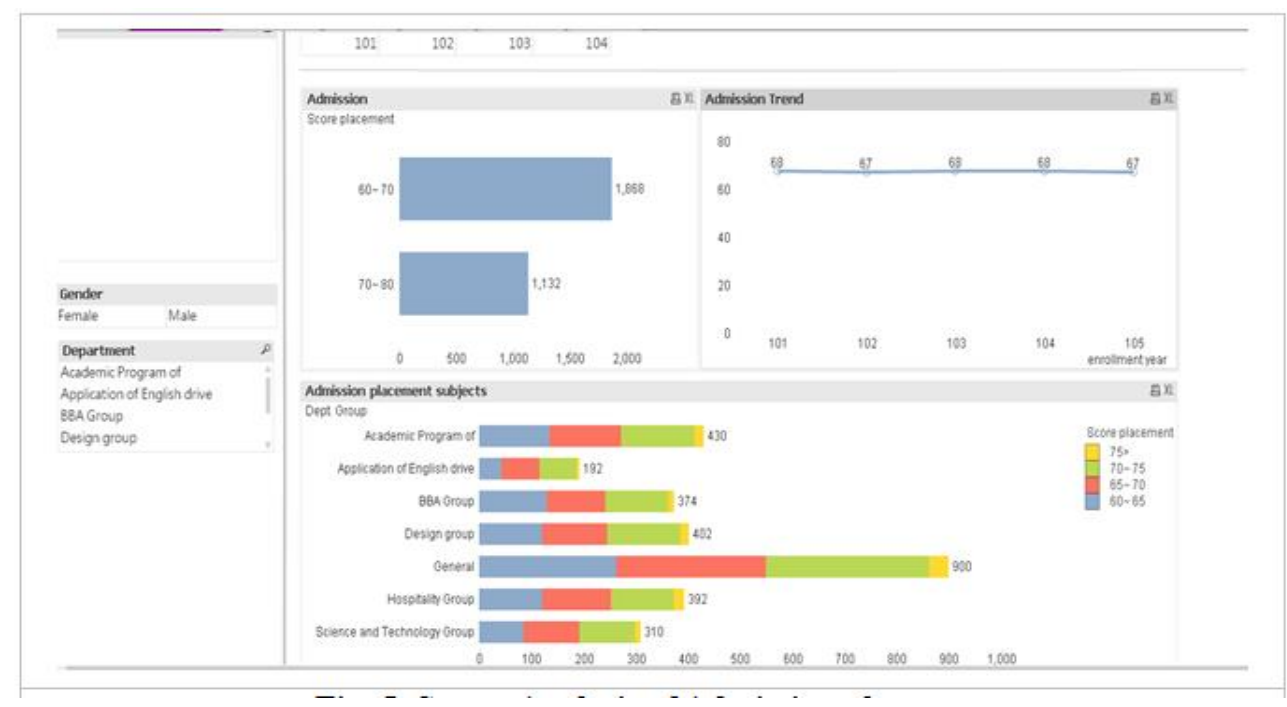

FIGURE 5 . Scores analysis of admission placement

Figure 6. is the analysis of the sources of students- school sources/regions. This analysis page can help school administrators to understand the sources of their students- school sources/regions in every academic year and then they can adjust their strategies of students' recruitment. The students' composition of the school sources/regions and the trend of students' composition can both be viewed clearly in the past 5 academic years since now.

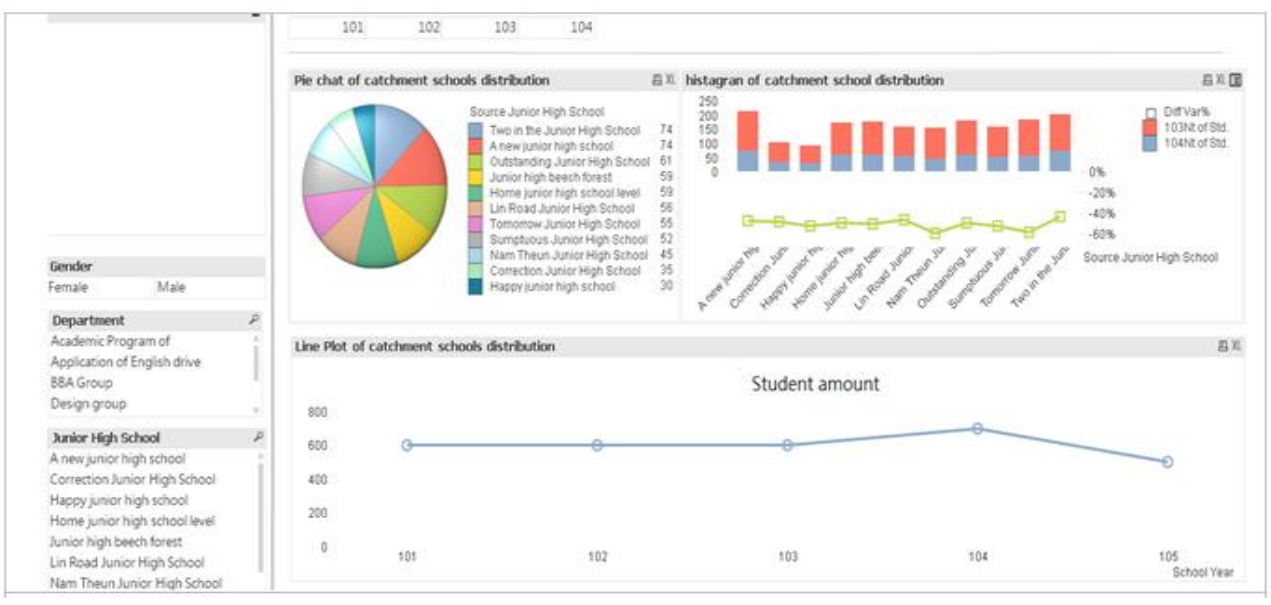

FIGURE 6 . Analysis of the sources of students-school sources/regions

The analysis of the ways of students choose for admission is as figure 7 shows. This analysis page is used to analyze all ways of students' admission and the trend of the ways. By this analysis, the school administrators can understand the outcome of students' admission ways in all departments. With the clear picture of this analysis, the administrators can adjust their amount of students' recruitment in the future. In other words, they can form and practice a more precise students' recruitment strategy. 


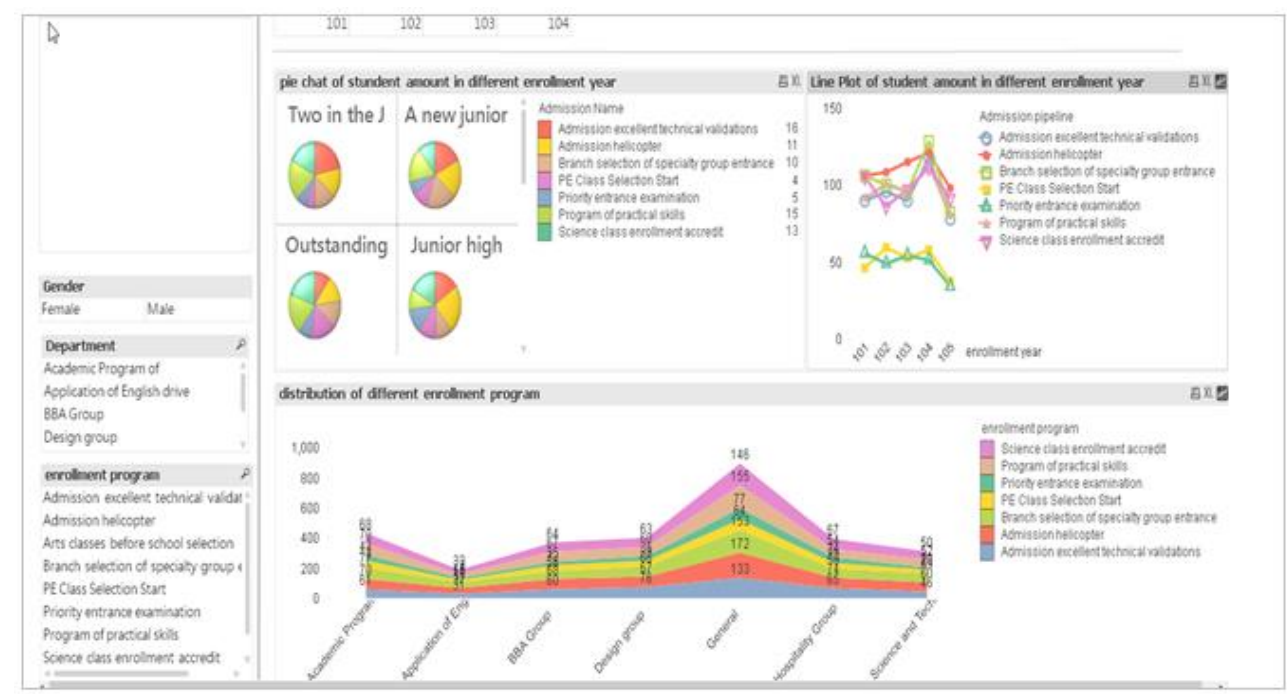

FIGURE 7 . Analysis of the ways of students choose for admission

\section{SUGGESTION}

A broad application of the Big Data analysis or IR in schools is suggested to be continued in the future. In this study, we take the module of enrollment source analysis as the main research topic. We suggest that more topics or facets as below need to be studied.

\section{Students Learning Achievement and their Life Adaptation}

By analyzing the learning achievement and their life adaptation of students from different schools and regions, we can adjust our student recruitment strategies in advance or to practice more effective instructional methods and guidance to help students adapt themselves to senior high school life.

Teachers' instructional quality: Through the analysis of teachers' instructional quality, objective and multiple assessments or suggestions can be offered to improve teachers' instructional quality.

School satisfaction: Longitudinal studies of students' school satis-faction are valuable data for a school to improve itself in all aspects. The research outcome of students' school satisfaction can be also used to adjust school's financial policy.

\section{CONCLUSION AND RECOMMENDATIONS}

An IR system can help school's administrators to form their decisions, policy and strategies of the students' recruitment, the improvement of students learning achievement, instructional quality and school satisfaction based on evidence. Education should continue changing and developing to keep the pace with environment. We hope this creative and brand-new trial on IR experiment in senior high schools can contribute to explore the potentials and limitations of IR on guiding school management strategies. Based on our research, in the future, more new creative concepts and techniques can be brought into educational area, and furthermore evidence-based decision makings can be encouraged and stressed. 


\section{REFERENCES}

Chen ,Yi-An. 2014. A study on meta-evaluation of senior-high school evaluation in Taipei City. Master dissertation, Grad- uate School of Educational Administration and Evaluation, University of Taipei, Taipei, Taiwan.

Chien, Yu-Fang. 2015. A study on the construction of professional competence indicators for pre-secondary school evaluators -Taipei City as an example. Master dissertation, Graduate School of Educational Administration and Evalu- ation, University of Taipei, Taipei, Taiwan.

Chiu, Chung-Hao. 2006. A study on school evaluation indicators of junior high and elementary school. Master disserta- tion, Department of Educational Policy and Administration, National Chi Nan University, Nantou, Taiwan.

Geiger, J. G. 2002. How data warehousing supports BI. In Business finance, vol. 8, Loveland, CO.

Jewel. 2015. Big data era. goo.gl/wGbXNh (accessed October 30, 2016).

Lin, ShuFang and Yih-Jeng Lin. 2016. A practical study on the school affairs decision system based on big data analysis.

Paper presented at the E-Learning and Information Technology Symposium, Southern Taiwan University of Science and

Technology, Tainan Taiwan.

Ministry of the Interior. 2016. Important indicators. URL: goo.gl/1eofXD. (accessed October 30, 2016).

Volkwein, F. 2015. Teaching and learning in IR courses: Myths vs. reality. Paper presented at the Forum of the Associa- $\quad$ tion for Institutional Research, Denver, CO.

Webber K. Calderon, A. Nauffal, D. Saavedra, M. Bramblett, S. and Borden, V. 2015. IR in the world around us. Paper presented at the Forum of the Association for Institutional Research, Denver, CO.

— This article does not have any appendix. - 